\title{
Fatigue Life Analysis of Aluminum Wheels by Simulation of Rotary Fatigue Test
}

\author{
Liangmo Wang* - Yufa Chen - Chenzhi Wang - Qingzheng Wang \\ School of Mechanical Engineering, Nanjing University of Science \& Technology, China
}

To improve the quality of aluminum wheels, a new method for evaluating the fatigue life of aluminum wheels is proposed in this paper. The ABAQUS software was used to build the static load finite element model of aluminum wheels for simulating the rotary fatigue test. The equivalent stress amplitude was calculated based on the nominal stress method by considering the effects of mean load, size, fatigue notch, surface finish and scatter factors. The fatigue life of aluminum wheels was predicted by using the equivalent stress amplitude and aluminum alloy wheel $S-N$ curve. The results from the aluminum wheel rotary fatigue bench test showed that the baseline wheel failed the test and its crack initiation was around the hub bolt hole area that agreed with the simulation. Using the method proposed in this paper, the wheel life cycle was improved to over $1.0 \times 10^{5}$ and satisfied the design requirement. The results indicated that the proposed method of integrating finite element analysis and nominal stress method was a good and efficient method to predict the fatigue life of aluminum wheels.

(C)2011 Journal of Mechanical Engineering. All rights reserved.

Key words: aluminum wheel, finite element analysis, static analysis, fatigue analysis

\section{INTRODUCTION}

Aluminum wheels should not fail during service. Their strength and fatigue life are critical. In order to reduce costs, design for light-weight and limited-life is increasingly being used for all vehicle components. In the actual product development, the rotary fatigue test is used to detect the strength and fatigue life of the wheel. Therefore, a reliable design and test procedure is required to guarantee the service strength under operational conditions and full functioning of the wheel.

Loads generated during the assembly may cause significant levels of stress in components. Under test conditions, these high levels of stress alter the mean stress level which in turn, alters the fatigue life and critical stress area of the components as well. Guo, Bhandarkar and Lin conducted finite element analysis and found that the inclusion of clamp load improves the prediction of the critical stress area and fatigue life of aluminum wheels [1]. Grubisic and Fischer examined wheel decisive parameters for design and durability, including operational loads, fatigue properties, which depend on material and manufacturing technology, and design [2]. Hsu, Wang and Liu proposed a probability-based model for predicting the fatigue failure of aluminum wheels. This model was intended to improve the prediction of the wheel fatigue life using simulation results and historical data. In their study, finite element models of 20 physcially tested aluminum wheels were constructed to simulate the dynamic radial fatigue test. Their mean stress level and stress amplitude during the fatigue loading cycles were calculated and plotted on a two dimensional plane. For a new wheel, the failure probability of the dynamic radial fatigue test can be read directly from this probability contour drawn from the test data [3]. Kocabicak and Firat proposed a bi-axial load-notch strain approximation for proportional loading to estimate the fatigue life of a passenger car wheel during the cornering fatigue test. The elasto-plastic strain components were calculated analytically using the total deformation theory of plasticity. The damage accumulation was calculated based on the Palmgren- Miner rule [4]. Raju et al. were concerned with generation of S-N curve for aluminum alloy (Al) A356.2-T6 and estimation of fatigue life under radial fatigue load. Finite element analysis (FEA) was carried out by simulating the test conditions to analyze the stress distribution and fatigue life of alloy wheels. The analytical results using FEA to predict the wheel fatigue life agreed well with the experimental 
results [5]. A mathematical model was developed to predict the residual stress distribution of an A356 alloy wheel, taking into account the residual stress evolution during the T6 quench process and redistribution of residual stress due to the material removal at the machining stage. The fatigue life of an A356 wheel was predicted by integrating the residual stress into the in-service loading and wheel casting defects (pores). The residual stress showed a moderate influence on the fatigue life of the wheel, which was more sensitive to casting pore size and service stress due to applied loads [6]. By improved Smith formula, Yang, Cui and Zhao used finite element analysis of stress values as the basic parameters for wheel fatigue life prediction. The wheel bending fatigue test results verified the method [7].

\section{ROTARY FATIGUE TEST}

In this paper, for predicting the wheel fatigue life, the nominal stress method was integrated into the CAD / CAE technology to simulate the rotary fatigue test. In addition, an actual prototype of the test was done to verify the analysis.

In the rotary fatigue test, a wheel was spun to bear a moment to simulate the process of turning corner continued the wheel's ability bearing the moment. According to the rotary fatigue test condition as specified in the SAE test procedure [8], a wheel was mounted on a rotating table. A shaft was attached to the center of the wheel where a constant normal force was applied as shown in Fig.1.

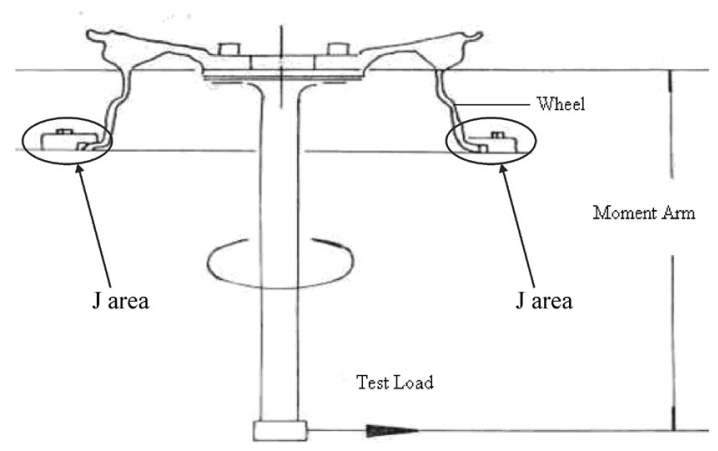

Fig.1. Layout of wheel rotary fatigue test

Test moment is calculated as follows [9]:

$$
\mathbf{M}=(\mu \mathbf{R}+d) F \lambda,
$$

where $M$ is the moment $(\mathrm{Nm})$, it is the strengthening moment the real vehicle bears; $\mu$ is the friction coefficient between tires and the road and set as $0.7 ; R$ is the tire static load radius (m); $d$ is the offset of wheel (m); $F$ is the maximum rated load $(\mathrm{N})$, which can be obtained by standards; $\lambda$ is the strength coefficient and set as 1.5. It is necessary to bear such a cycle load $1.0 \times 10^{5}$ times with no visible crack.

\section{MATERIAL PROPERTIES AND MANUFACTURING OF ALUMINUM ALLOY WHEEL}

\subsection{A356 Aluminum Alloy}

The aluminum alloy A356 is widely used in the wheel industry, its solidification temperature ranges from 550 to $615{ }^{\circ} \mathrm{C}$ and its volume shrinkage is about $6 \%$. Tables 1 and 2 show the components of A356 cast aluminum alloy and the mechanical performance of these components [9].

\subsection{Foundry Technology}

Gravity casting and low-pressure casting are the two major approaches to case aluminum alloy wheels. Gravity casting presses molten metal into mold by gravity, while low-pressure casting uses low-pressure of air instead of gravity for molding. Of these two approaches, low-pressure casting has a higher utilization ratio of molten aluminum alloy, and higher levels of mechanical quality, surface hardness, and accuracy of dimension and smooth surface, so it is a major method to produce aluminum alloy wheels.

Low-pressure permanent mold casting uses a gas at low pressure, usually between 21 and $100 \mathrm{kPa}$ to push the molten metal into the mold cavity. The pressure is applied to the top of the pool of liquid, which forces the molten metal up a refractory pouring tube and finally into the bottom of the mold. The pouring tube extends to the bottom of the ladle, so that the aluminum being pushed into the mold is exceptionally clean. The speed of aluminum being pushed into the mold is usually controlled in the range of 30 to $70 \mathrm{~mm} / \mathrm{s}$ to ensure that the molten aluminum flows smoothly and the air exhausts out [10]. 
Table 1. The components of A356 cast aluminum alloy (GB/T 1173-1995)

\begin{tabular}{|c|c|c|c|c|c|c|c|c|}
\hline Elements & $\mathrm{Si}$ & $\mathrm{Mg}$ & $\mathrm{Ti}$ & $\mathrm{Fe}$ & $\mathrm{Cu}$ & $\mathrm{Zn}$ & $\mathrm{Mn}$ & $\mathrm{Al}$ \\
\hline $\begin{array}{c}\text { Weight } \\
{[\%]}\end{array}$ & $6.5 \sim 7.5$ & $0.25 \sim 0.45$ & $0.08 \sim 0.20$ & $\leq 0.2$ & $\leq 0.1$ & $\leq 0.1$ & $\leq 0.1$ & Others \\
\hline
\end{tabular}

Table 2. The mechanics performance of A356 cast aluminum alloy (GB/T 1173-1995)

\begin{tabular}{|c|c|c|c|c|c|}
\hline \multirow{2}{*}{ Alloy } & \multirow{2}{*}{$\begin{array}{c}\text { Foundry } \\
\text { method }\end{array}$} & \multirow{2}{*}{$\begin{array}{c}\text { Heat } \\
\text { treatment }\end{array}$} & $\begin{array}{c}\text { Tensile strength } \\
\sigma_{\mathrm{b}}[\mathrm{MPa}]\end{array}$ & $\begin{array}{c}\text { Elongation } \delta_{\mathrm{s}} \\
{[\%]}\end{array}$ & $\begin{array}{c}\text { Brinell hardnessHBS } \\
(5 / 250 / 30)\end{array}$ \\
\hline $\begin{array}{c}\text { ZAlSi7MgA } \\
(\mathrm{A} 356)\end{array}$ & $\begin{array}{c}\text { Metal Mold } \\
\text { casting }\end{array}$ & $\mathrm{T} 6$ & 225 & 3 & 80 \\
\hline
\end{tabular}

\subsection{Heat Treatment Technology}

T6 Heat Treatment is a specific heat treatment process which can be applied to aluminum wheels. The T6 heat treatment for aluminum wheels commonly includes solution treatment, quench and artificial aging.

Solution treatment can dissolve the alloying elements, get supersaturated and instable solid solution phase, in order to enhance the effect of subsequent aging. The solution treatment temperature needs to exceed the solid solution temperature. The higher the temperature is, the better the effect of solution treatment is. But the treatment temperature cannot exceed that of the solidus, otherwise, the mechanical performance of the wheel will distinctly decline due to overheating or oversintering. In this phase the alloy wheel is heated to $535 \pm 5^{\circ} \mathrm{C}$ for 3 to 4 hours. In the quench phase, quenching temperature cannot be too low, otherwise, excessive internal stress will result in deformation and cracking, and the quenching time should be as short as possible. The wheel is water quenched less than $15 \mathrm{~s}$, and the water temperature is $60^{\circ} \mathrm{C}$. Finally, in the artificial aging, the strength and hardness of aluminum alloy are improved because the supersaturated solid solution decomposes as time increases. If the aging temperature is too high, the elongation of aluminum alloy will decrease. However, if the aging temperature is too low, the yield strength and tensile strength will decline. In T6 heat treatment condition, temperature is kept at $165 \pm 5{ }^{\circ} \mathrm{C}$ for 3 to $4 \mathrm{~h} \mathrm{[10]}$.

\section{FINITE ELEMENT MODELING BASED ON ROTARY FATIGUE TEST}

Based on the wheel dynamic bending fatigue test, the finite element models of automotive wheels under the static load are constructed, and the I-DEAS software is used to perform the stress analysis [11] and [12]. In this paper, the stress analysis was performed by using a commercial FEA software ABAQUS. ABAQUS is powerful engineering finite element simulation software with a library of rich elements that can be used to simulate any geometry and typical engineering properties of materials. The software provides solutions to problems ranging from relatively simple linear analysis to many complex non-linear problems [13].

\subsection{Element Type and Material Properties}

The wheel is meshed using second-order mend tetrahedral elements (C3D10M), with an element size of $10 \mathrm{~mm}$, which can be refined locally. There are a total of 167,817 C3D10M elements. The shaft is modeled using C3D8R element, with an element size of $20 \mathrm{~mm}$. There are a total of 3,162 C3D8R elements [13].

\subsection{Wheel Meshing}

When the wheel is meshed, in estimated data change gradient big spot, it needs to adopt more intensive grid to better reflect the changes of data. In the wheel hub, the danger zones are rim, junction with rim and rib, and the areas 
around bolt hole. The stress concentration region corresponding grid distribution should be dense; but the rim the stress cannot consider nearly in the entire parsing process, the corresponding grid distribution should be sparse (shown in Fig. 2).

a)

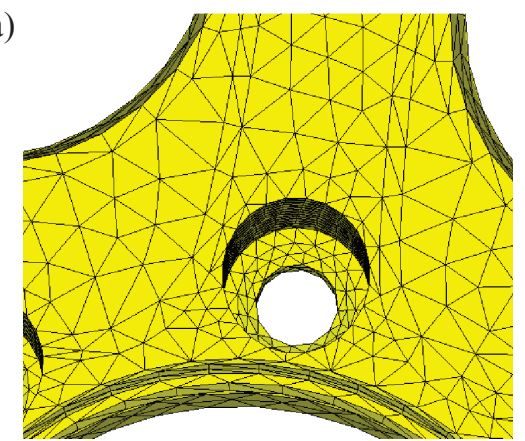

b)

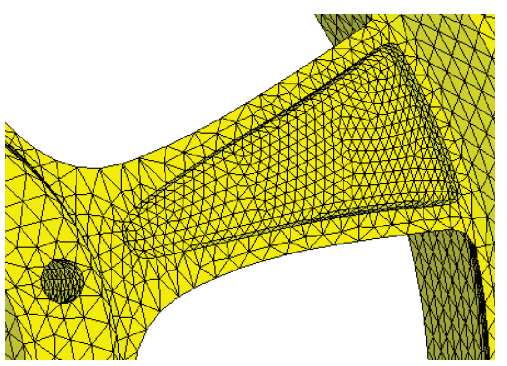

c)

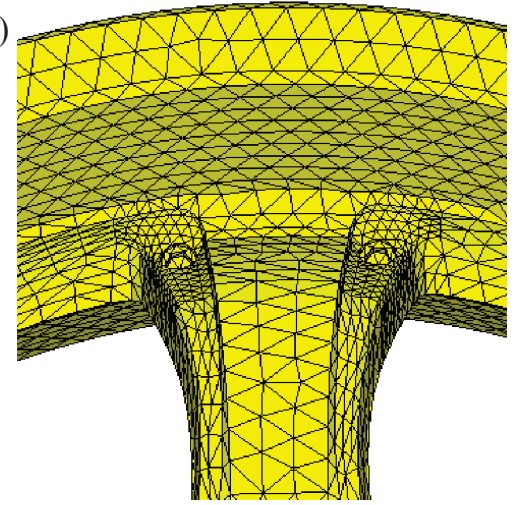

Fig. 2. Wheel meshing; a) bolt hole, b) rib, c) junction with rim and rib

\subsection{Loads and Boundary Conditions [1]}

In the FEA model, loading and boundary conditions were set up similarly to those in the bench test. The wheel was constrained around flange edge of the rim and loaded with a constant force at the end of the shaft, see Fig. 3. The load shaft and wheel were connected by bolts. Due to the main concern being wheel deformation, the load shaft in the FEA analysis was defined as a rigid body, using tie connection with wheel. J area under the wheel rim was under full constraints.

In aluminum alloy wheel fatigue test, $1 \times 10^{5}$ cycles were conducted. To simulate the cycle, there were 16 load cases, each interval was $22.5^{\circ}$, and wheel responses were calculated respectively. As shown in Fig. 3, the direction at $0^{\circ}$ gave the positive direction of $\mathrm{x}$ axis from the original direction of cyclical loading force in the simulation. Then, the force loaded counterclockwise with an intersection of $22.5^{\circ}$ which was sufficient to reflect the real stress distribution.

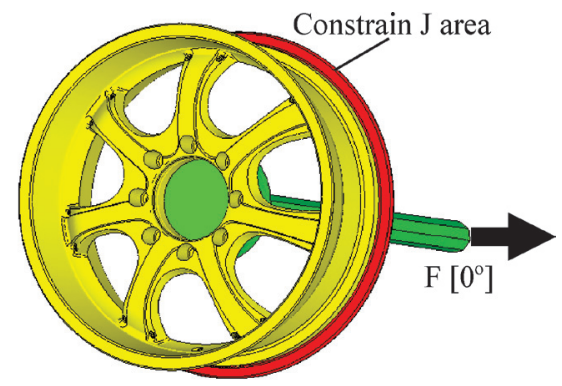

Fig. 3. Finite element model

\section{STATIC ANALYSIS}

\subsection{Baseline Design}

When the wheel endured the dynamic bending moment, load direction and maximum stress place changed over time. According to the pre-process, the circumference was divided into 16 sections and the information of stress and location was calculated. As the wheel structure was complex, Von Mises stress was used.

The node with maximum wheel stress at the 16 load cases was exactly the damage area. Because the wheel structure was symmetrical, only eight load cases were analyzed. Figs. 4 and 5 show the wheel stress and stress local at the loading direction of $0^{\circ}$.

The maximum stress was $152.54 \mathrm{MPa}$ in the node 111606, which was in the hub bolt hole area. According to the bench test, this area was also where the crack damage occurred to the wheel. Therefore, the result from the FEA was reliable. The remaining stress figures were 
omitted. The principal stress was not considered in this location because Von Mises stress criteria was sufficient.

The maximum stress level of wheel key nodes was shown in Table 3. Stress concentration, weakness and possible fatigue cracks were presented in this table.

\subsection{Improved Design}

According to the FEA results of the baseline design, the aluminum alloy wheel design could be improved by reinforcing the weaker area and revising the geometry of rib and notch.

Fig. 6 shows the wheel stress at the loading direction of $0^{\circ}$. The maximum stress was 143.64

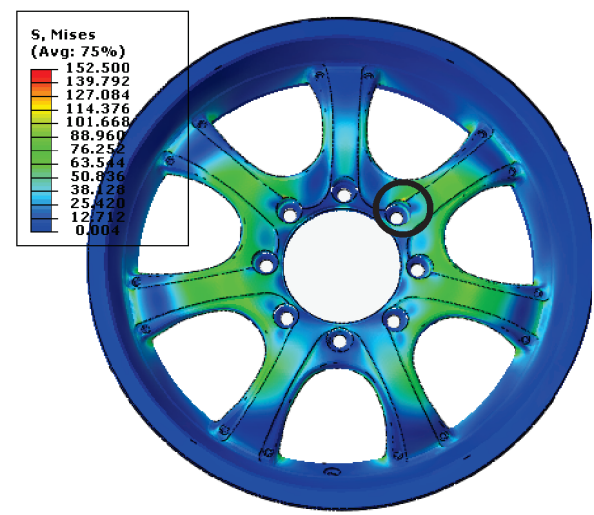

Fig. 4. Node:11606,152.54MPa [0 $]$
MPa in the node 192061 which was in the hub bolt hole area same as the baseline design. Table 4 shows the maximum stress level of wheel key nodes. It can be seen that the maximum stress level of the improved wheel design using FEA is smaller than that of the baseline design in all load cases.

\section{FATIGUE ANALYSIS [11] and [15] to [18]}

The main methods to determine the model fatigue life are fatigue life test and fatigue life analysis. Fatigue life test has a high-cost and long cycle. Fatigue life analysis is based on the fatigue properties of materials and load time histories. It can predict fatigue life at the product design stage,

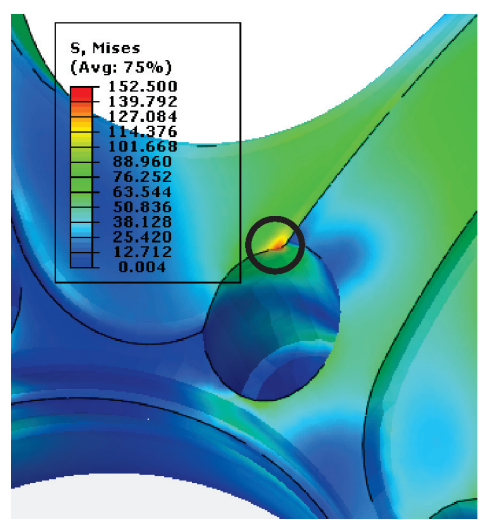

Fig. 5. Stress local figure $\left[0^{\circ}\right]$

Table 3. The maximum stress value of wheel key nodes (Baseline design) [MPa]

\begin{tabular}{|c|r|r|r|r|r|r|r|r|r|}
\hline \multicolumn{1}{|c|}{$0^{\sigma_{\max }}$} & \multicolumn{1}{c|}{$0^{\circ}$} & $22.5^{\circ}$ & \multicolumn{1}{|c|}{$45^{\circ}$} & $67.5^{\circ}$ & \multicolumn{1}{|c|}{$90^{\circ}$} & $112.5^{\circ}$ & $135^{\circ}$ & $157.5^{\circ}$ & \multicolumn{1}{c|}{$180^{\circ}$} \\
\hline 111606 & 152.54 & 164.82 & 89.04 & 116.06 & 64.45 & 1.88 & 37.33 & 117.04 & 152.54 \\
\hline 7986 & 64.75 & 101.76 & 72.74 & 128.14 & 112.99 & 81.24 & 22.92 & 23.28 & 64.75 \\
\hline 8024 & 51.31 & 18.34 & 30.69 & 92.05 & 118.99 & 128.33 & 69.43 & 91.21 & 51.31 \\
\hline 6059 & 3.07 & 31.40 & 34.54 & 77.61 & 139.90 & 78.48 & 35.47 & 33.48 & 3.07 \\
\hline 278799 & 147.62 & 113.16 & 36.02 & 2.04 & 60.71 & 112.56 & 86.28 & 159.60 & 147.62 \\
\hline
\end{tabular}

Table 4. Maximum stress value of wheel key nodes (Improved design) [MPa]

\begin{tabular}{|c|r|r|r|r|r|r|r|r|r|}
\hline \multicolumn{1}{|c|}{$\sigma_{\text {max }}$} & \multicolumn{1}{|c|}{$0^{\circ}$} & $22.5^{\circ}$ & $45^{\circ}$ & $67.5^{\circ}$ & $90^{\circ}$ & $112.5^{\circ}$ & $135^{\circ}$ & $157.5^{\circ}$ & $180^{\circ}$ \\
\hline 192061 & 143.64 & 150.13 & 83.78 & 109.14 & 58.68 & 13.34 & 35.25 & 110.28 & 143.64 \\
\hline 13037 & 21.27 & 43.14 & 34.34 & 135.40 & 61.97 & 49.31 & 17.13 & 6.01 & 21.27 \\
\hline 11096 & 17.88 & 54.46 & 53.97 & 116.90 & 124.34 & 113.23 & 50.02 & 45.98 & 17.88 \\
\hline 207190 & 48.21 & 16.97 & 31.70 & 93.27 & 119.25 & 127.51 & 68.35 & 88.57 & 48.21 \\
\hline 238613 & 143.41 & 110.09 & 35.16 & 15.56 & 58.58 & 108.99 & 83.66 & 154.90 & 143.41 \\
\hline
\end{tabular}


reduce the number of experimental prototypes, and shorten the development cycle. Fatigue life analysis includes nominal stress analysis, crack initiation analysis, stress-strain field intensity and energy law [14].

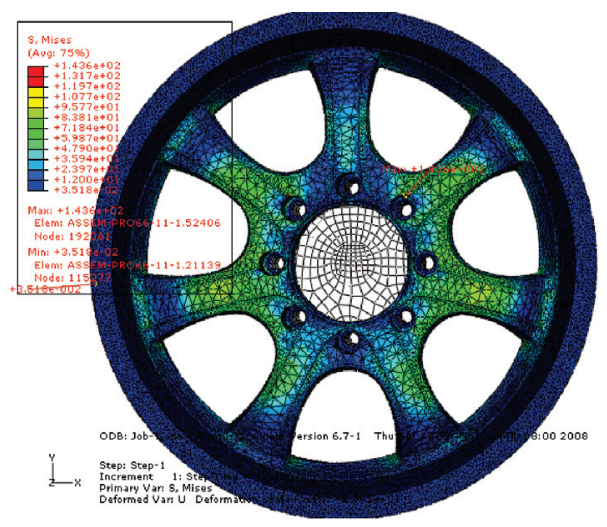

Fig. 6. $0^{\circ}$ Node192061, 143.64 [MPa]

In this paper, a method that combined nominal stress analysis and static analysis was used to predict wheel fatigue life.

\subsection{Material S-N Curve}

In high-cycle fatigue situations, materials performance is commonly characterized by an $S-N$ curve, also known as a Wöhler curve. This is a graph of the magnitude of a cyclical stress (S) against the logarithmic scale of cycles to failure (N).

In the absence of test data, some special points can be obtained from the basic material performance parameters, and then material S-N curve can be obtained by connecting them.

When $N \leq 1 \times 10^{3}, \sigma_{-1 N}=0.9 \sigma_{b}$.

When $N \geq N_{0}, \sigma_{-1 N}=\sigma_{-1}$.

When $1 \times 10^{3} \leq N \leq N_{0}$, S-N curve can be obtained by connecting two points $\left(N=1 \times 10^{3}\right.$, $\sigma_{-1 N}=0.9 \sigma_{b}$ and $N=N_{0}, \sigma_{-1 N}=\sigma_{-1}$ ) and calculated using the following equation:

$$
\lg \sigma_{-1 N}=\lg \sigma_{-1}+\frac{\lg N_{0}-\lg N}{\lg N-3}\left[\lg \left(0.9 \sigma_{b}\right)-\lg \sigma_{-1}\right] .
$$

$N$ is stress or strain cycle. The cycle $N_{0}$ corresponds to the breaking point of material. $\sigma_{-1 N}$ is the limited life material limit of fatigue under symmetric cycle. $\sigma_{-1}$ is the material limit of fatigue under symmetric cycle.

Therefore, the basic material $S-N$ curve can be established as depicted in Fig.7.

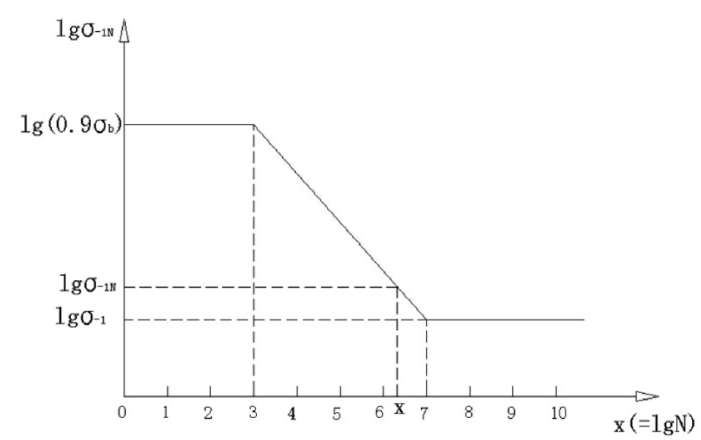

Fig.7. Material $S-N$ curve

The strength limit $\sigma_{b}$ of material A356 is $250 \mathrm{MPa}$. The symmetrical bending fatigue limit $\sigma_{-1}$ is $120 \mathrm{MPa}$. $N_{0}$ can be obtained as $1 \times 10^{7}$.

\subsection{Influencing Factors}

Component size factor $\varepsilon$ : Component fatigue strength decreases as component size increases. Component size has a distinct effect on part fatigue strength. Therefore, size factor describes the size effect on fatigue strength.

When $N \geq N_{0}$, for bending and torsion, $\varepsilon_{N}=$ $\varepsilon$, where $\varepsilon$ and $\varepsilon_{N}$ give the size factors of unlimited life design and limited life design respectively. When $N \leq 1 \times 10^{3}, \varepsilon_{N}=1$. When $N=1 \times 10^{3}$ to $N_{0}$, points $1 \times 10^{3}$ corresponding to 1 and $N_{0}$ corresponding to $\varepsilon$ are connected on coordinates, and the corresponding life of $\varepsilon_{N}$ can be obtained from the ratio curve. In this case, according to the wheel size, $\varepsilon$ is 0.68 .

Fatigue notch factor $K_{f}$ : In the stress-life approach the effect of notches is accounted for by the fatigue notch factor, $K_{f}$ : This value relates the unnotched fatigue strength of a member to its notched fatigue strength at a given life. $K_{f}$ can be calculated by using the following Eq.:

$$
K_{f}=1+q\left(K_{t}-1\right)
$$

where $q-a$ notch sensitivity factor; $K_{t}$ the theoretical stress concentration factor.

The original fatigue location always occurs at the stress-concentrated area. Fatigue notch factor is usually used to express the 
reduction in fatigue strength of part notch. When $N \leq 1 \times 10^{3}, K_{f N}=1$. When $N=1 \times 10^{3}$ to $N_{0}$, points $1 \times 10^{3}$ corresponding to 1 and $N_{0}$ corresponding to $K_{f}$ are connected on coordinates, and the corresponding life of $K_{f N}$ can be obtained from the ratio curve. When $N \geq N_{0}, K_{f N}=K_{f}$. In this case, $K_{f}=1.1$.

Surface finish factor $\beta$ : Part surface state has prominent effect on fatigue strength, so surface factor is used to describe the effect degree. When $N \leq 1 \times 10^{3}, \beta_{N}=1$. When $N=1 \times 10^{3}$ to $N_{0}$, connect points $1 \times 10^{3}$ corresponding to 1 and $N_{0}$ corresponding to $\beta$ on coordinate, obtain corresponding life of $\beta_{N}$ from the ratio curve. When $N \geq N_{0}, \beta_{N}=\beta$. In this case $\beta$ is 0.95 .

Scatter factor $K_{s}$ : Material property, heat treatment, machining process, and so forth have errors, so scatter factor $K_{S N}$ is considered. When $N \leq 1 \times 10^{4}, K_{s N}=K_{s l}$. When $N \geq 1 \times 10^{5}$, $K_{s N}=K_{s 2}$. For aluminum alloy wheels which are casted, $K_{s 1}=1.3, K_{s 2}=1.6$. When $N=1 \times 10^{4}$ to $1 \times 10^{5}$, connect points $1 \times 10^{4}$ corresponding to 1.3 and $1 \times 10^{5}$ corresponding to 1.6 on coordinate, obtain corresponding life of $K_{S}$ from the ratio curve.

\subsection{Component S-N Curve}

Based on material S-N curve, component S-N curve can be obtained by considering size factor, fatigue notch factor, surface finish factor and scatter factor.

First, $\sigma_{-1 D}$ is not corrected when $N=1$, $1 \times 10^{3}$. When $N=N_{0}, \sigma$ needs to divide fatigue strength coefficient $K_{\sigma D}$. Then, the adjacent points are connected, the component $S-N$ curve can be obtained without considering the scatter factor. The component $S-N$ is calculated using the following Eq.:

$$
\lg \sigma_{-1 D N}=\lg \sigma_{-1 D}+\frac{\lg N_{0}-\lg N}{\lg N_{0}-3}\left[\lg \left(0.9 \sigma_{b}\right)-\lg \sigma_{-1 D}\right] \text {, }
$$

where $\sigma_{-1 D}=\sigma_{-1} / K_{\sigma D}$ and $K_{\sigma D}=\frac{K_{f N}}{\varepsilon_{N}}+\frac{1}{\beta_{N}}-1$.

After all, $N=1,10^{3}, 10^{4}$, using the $\sigma$ divides scatter factor $K_{s 1} ; N=10^{5}, N_{0}$, using the $\sigma$ divides scatter factor $K_{s 2}$. Therefore, a modified component $S-N$ curve can be obtained by connecting two adjacent points as shown in Fig. 8.

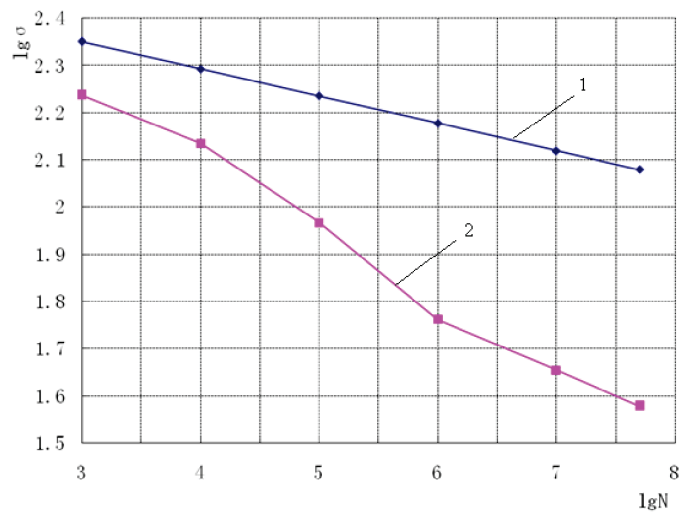

Fig. 8. Component $S-N$ curve (1 material $S-N$ curve 2 component $S$ - $N$ curve)

\subsection{Equivalent Cycle Stress and Fatigue Life}

Wheel fatigue strength is determined by the maximum stress $\sigma_{\max }$ and minimum stress $\sigma_{\min }$ of weakness spot. Based on the nominal stress analysis for predicting wheel fatigue life, weakness spot $S-N$ curve is suitable to symmetrical loads.

According to the influence of medium stress and fatigue strength decreasing coefficient, any asymmetric cycle stress has an equivalent cyclic stress amplitude $\sigma_{a e}$ which can be calculated by using Eq. (5). Therefore, the problem of asymmetric cycle stress can be translated to symmetry cycle stress.

$$
\sigma_{a e}=K_{\sigma D} \sigma_{a}+\psi_{a} \sigma_{m},
$$

where $\sigma_{a}=\left(\sigma_{\max }-\sigma_{\min }\right) / 2, \sigma_{a}$ is the stress amplitude; $\sigma_{m}=\left(\sigma_{\max }-\sigma_{\min }\right) / 2, \sigma_{m}$ is the mean stress.

$\Psi_{\sigma}$ is the equivalent factor which is used to convert medium stress to equivalent stress amplitude. It is related to material properties and calculated as follows:

$$
\psi_{\sigma}=\sigma_{-1} /\left(\sigma_{b}+350\right)
$$

Where $\sigma_{-1}$ is the material fatigue limit; $\sigma_{b}$ is strength limit.

Considering the equivalent stress $\sigma_{a e}$ in the component $\mathrm{S}-\mathrm{N}$ curve, the value at abscissa is the fatigue life. 


\subsection{Fatigue Analysis and Test Correlations [12]}

Based on the previous static analysis results, equivalent symmetric cycle stress amplitude of maximum stress amplitude node can be calculated. Considering the equivalent stress in the component $S-N$ curve, the fatigue life is obtained.

Tables 5 and 6 give the equivalent stress amplitude and fatigue life results of the baseline and improved designs. The results showed that the fatigue life of baseline design was less than $1 \times 10^{5}$ cycles and failed to meet the design requirement for aluminum alloy wheels. While the fatigue life of the improved design using FEA was greater than $1 \times 10^{5}$ cycles, satisfying the design requirement.

To validate the prediction of fatigue life, wheel rotary fatigue test was conducted. The test results showed that the prediction of fatigue life using FEA was consistent with the result of bench test.

\section{CONCLUSION}

A fatigue lifetime prediction method of aluminum alloy wheels was proposed to ensure their durability at the initial design stage. To simulate the rotary fatigue test, static load FEM model was built using ABAQUS. The analysis results showed that the maximum stress area was located in the hub bolt hole area agreed with the fact. Therefore, the finite element model can achieve results consistent with that obtained from the actual static load test.

The nominal stress method was used to predict the fatigue life of aluminum alloy wheels. In the nominal stress method, the fatigue life of aluminum wheels was predicted by using aluminum alloy wheel $S-N$ curve and equivalent stress amplitude. The simulation result showed that baseline design fatigue life was lower than $1 \times 10^{5}$. After improving the weakness area of aluminum alloy wheels, the improved wheel life cycle exceeded $1 \times 10^{5}$ and satisfied the design requirement.

Aluminum alloy wheel rotary fatigue bench test was conducted. The test result showed that the prediction of fatigue life was consistent with the physical test result. These results indicate that the fatigue life simulation can predict weakness area and is useful for improving aluminum alloy wheel. These results also indicate that integrating FEA and nominal stress method is a good and efficient method to predict aluminum alloy wheels fatigue life.

\section{List of notation}

$D$ the offset of wheel [m]

$F$ the maximum rated load [N]

$K_{f}$ fatigue notch factor

$q$ a notch sensitivity factor

$K t$ the theoretical stress concentration factor

$K_{f N}$ fatigue reducing factor

$K_{s N}$ scatter coefficient

Table 5. Equivalent stress and fatigue life of wheel dangerous nodes (Baseline design)

\begin{tabular}{|c|c|c|c|c|c|c|}
\hline Node & $\sigma_{\max }[\mathrm{MPa}]$ & $\sigma_{\min }[\mathrm{MPa}]$ & $\sigma_{a}[\mathrm{MPa}]$ & $\sigma_{m}[\mathrm{MPa}]$ & $\sigma[\mathrm{MPa}]$ & life [cycle] \\
\hline 111606 & 164.82 & 1.88 & 81.52 & 83.47 & 98.19 & 64486 \\
\hline 7986 & 128.14 & 22.92 & 52.64 & 75.56 & 67.73 & 439542 \\
\hline 8024 & 128.33 & 18.34 & 55.01 & 73.35 & 69.76 & 379627 \\
\hline 6059 & 139.97 & 3.07 & 82.75 & 68.41 & 71.52 & 155779 \\
\hline 278799 & 159.60 & 2.04 & 78.89 & 80.83 & 94.95 & 76531 \\
\hline
\end{tabular}

Table 6. Equivalent stress and fatigue life of wheel dangerous nodes (Improved design)

\begin{tabular}{|c|c|c|c|c|c|c|}
\hline node & $\sigma_{\max }[\mathrm{MPa}]$ & $\sigma_{\min }[\mathrm{MPa}]$ & $\sigma_{a}[\mathrm{MPa}]$ & $\sigma_{m}[\mathrm{MPa}]$ & $\sigma[\mathrm{MPa}]$ & life [cycle] \\
\hline 192061 & 150.13 & 13.34 & 68.39 & 81.73 & 84.74 & 137780 \\
\hline 13037 & 135.40 & 6.01 & 64.77 & 70.70 & 78.84 & 200198 \\
\hline 11096 & 124.34 & 17.88 & 53.20 & 71.12 & 67.42 & 448512 \\
\hline 207190 & 127.51 & 16.97 & 55.32 & 72.24 & 69.70 & 378053 \\
\hline 238613 & 154.90 & 15.56 & 69.67 & 85.23 & 86.72 & 122309 \\
\hline
\end{tabular}


$K_{\sigma D}$ the fatigue reducing factor of component

$M$ the moment [Nm]

$R \quad$ the tire static load radius [m]

$N$ stress or strain cycles before fatigue failure

$N_{0}$ the cycle is corresponding to the breaking point of material

$S-N$ Wohler curve

$\beta$ surface finish factor

$\beta_{N}$ surface finish coefficient:

$\varepsilon \quad$ the size factors of unlimited life design

$\varepsilon_{N}$ the size factors of limited life design

$\lambda$ the strengthening coefficient

$\mu$ the friction coefficient between tires and the road

$\sigma \quad$ equivalent cyclic stress

$\sigma_{a}$ the stress amplitude

$\sigma_{\max }$ the maximum stress

$\sigma_{b}$ strength limit

$\sigma_{f}$ the real fracture stress

$\sigma_{m}$ the mean stress

$\sigma_{-1}$ fatigue limit

$\sigma_{-1 N}$ fatigue strength at $\mathrm{N}$ cycles

$\sigma_{a e}$ equivalent cyclic stress amplitude

$\Psi_{\sigma}$ the equivalent factor which is used to convert medium stress to equivalent stress amplitude.

\section{REFERENCES}

[1] Guo, M., Bhandarkar, R., Lin, B. (2004). Clamp load consideration in fatigue life prediction of a cast aluminum wheel using finite element analysis. Society of Automotive Engineer, Inc. Warrendale, Pennsylvania.

[2] Grubisic, V., Fischer, G. (1998). Design criteria and durability approval of wheel hubs. Society of Automotive Engineer, Inc. Warrendale, Pennsylvania.

[3] Hsu, Y.-L., Wang, S.-G., Liu, T.-C. (2004). Prediction of fatigue failure of aluminum disc wheel using the failure probability contour based on historical test data. Journal of the Chinese Institute of Industrial Engineers, vol. 21, no. 6, p. 551-558.

[4] Kocabicak, U., Firat, M. (2001). Numerical analysis of wheel cornering fatigue tests, Engineering Failure Analysis, vol. 8, p. 339354.

[5] Ramamurty Raju, P., Satyanarayana, B., Ramji, K., Suresh Badu, K. (2007).
Evaluation of fatigue life of aluminum alloy wheels under radial loads. Engineering Failure Analysis, vol. 14, p. 791-800.

[6] Li, P., Maijer, D.M., Lindley, T.C., Lee, P.D. (2007). Simulating the residual stress in an A356 automotive wheel and its impact on fatigue life. Metallurgical and Materials Transactions B, vol. 38B, no. 8, p. 505-515.

[7] Zhanchun, Y., Shengming, C., Guifan, Z. (2000). Prediction of automobile wheel fatigue life with improved smith equation. Journal of Harbin Institute of Technology, vol. 32 , no. 6 , p. 100-102.

[8] SAE J328 Revised 1994: Wheels-Passenger car and truck performance requirements and test procedures.

[9] GB/T 1173-1995, Casting Aluminum Alloy.

[10] Yutao, Z. (2004). Aluminum alloy wheel manufacturing technology, China Machine Press, Beijing.

[11] Cuixia, Z. (2006). Design and structural analysis of aluminum alloy wheel, Dissertation, Zhejiang University, Zhejiang.

[12] Xiaofeng, W., Zhao, L., Xiaoge, Z. (2007). Finite element analysis of a wheel based on the wheel dynamic cornering fatigue test. Tractor \& Farm Transporter, vol. 34, no. 1, p. 45-47.

[13] Tenglun, Z. (2007). The application of ABAQUS 6.6 in mechanical engineering, China Water Power Press, Beijing.

[14] Karandikar, H.M. (1990). Fatigue life prediction for wheels by simulation of the rotating bending test. Society of Automotive Engineer, Warrendale, Pennsylvania.

[15] Bannantine, J.A., Corner, J.J., Handrock, J.L. (1990). Fundamentals of metal fatigue analysis, Prentice Hall, New Jersey.

[16] Pook, L. (2007). Metal fatigue: what it is, why it matters, solid mechanics and its applications, Springer Verlag, Berlin.

[17] Stephens, R.I., Fatemi, A., Stephens, R.R., Fuchs, H.O., Faterni, A. (2000). Metal fatigue in engineering, 2nd Edition, WileyInterscience.

[18] Zhao, S., Wang, Z. (1997). Fatigue design. Mechanical Industrial Press,. 